\title{
Morphometric Assessment of Human Corpus Callosum on Cadaveric Brain Specimens
}

\author{
Pradipta Ray Choudhury ${ }^{1}$, Purujit Choudhury², Prabahita Baruah ${ }^{3}$ \\ ${ }^{1}$ Department of Anatomy, Silchar Medical College and Hospital, Silchar, Cachar, Assam, India. \\ ${ }^{2}$ Department of Surgery, Gauhati Medical College and Hospital, Guwahati, Assam, India. \\ ${ }^{3}$ Department of Anatomy, Silchar Medical College and Hospital, Silchar, Cachar, Assam, India.
}

\section{ABSTRACT}

\section{BACKGROUND}

Corpus callosum is the main commissural tract between the two halves of the brain and assumes an essential job in transferring sensory, motor, and cognitive data from identical regions in the two brain hemispheres. Literature on the issue of the human corpus callosum sexual dimorphism is not universal. Similarly, age related change in corpus callosum measurements is also not consistent.

\section{METHODS}

Different diameters of brain and corpus callosum like longitudinal and vertical diameters of brain and length, height, widths of corpus callosum etc. were measured with digital vernier caliper.

\section{RESULTS}

37 brains were collected, out of which 24 were male \& 13 were female brains of various ages between 20 years and 70 years of age. Average longitudinal \& vertical diameters of brain specimens under study were $158.29 \mathrm{~mm}$ and $102.41 \mathrm{~mm}$ respectively and average length of corpus callosum was $72.19 \mathrm{~mm}$. Change in length of corpus callosum in relation to gender is not significant with $p$ value $>0.05$. There is decrease in length of corpus callosum after 65 years of age.

\section{CONCLUSIONS}

Positive linear correlation was observed between length of corpus callosum and the length \& vertical diameters of brain. The study has failed to establish statistically significant gender differentiation in the diameters of corpus callosum. Also, there was decrease in the length of corpus callosum (EZ) in 65 years and above age group with decrease in height and width of body as well as splenium of corpus callosum between 50 - 60 years age group.

\section{KEY WORDS}

Corpus Callosum, Age, Sexual Dimorphism
Corresponding Author: Dr. Purujit Chaudhury, Department of Surgery, Gauhati Medical College and Hospital, Guwahati, Assam, India.

E-mail: prcanatomist@gmail.com

DOI: 10.14260/jemds/2020/89

Financial or Other Competing Interests: None.

How to Cite This Article:

Choudhury PR, Choudhury P, Baruah P. Morphometric assessment of human corpus callosum on cadaveric brain specimens. J. Evolution Med. Dent. Sci. 2020;9 (07):388392, DOI: $10.14260 /$ jemds/2020/89

Submission 26-12-2019,

Peer Review 25-01-2020,

Acceptance 28-01-2020,

Published 17-02-2020.

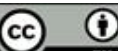




\section{BACKGROUND}

Corpus callosum (CC) is the main commissural tract between the two halves of the brain and assumes an essential job in transferring sensory, motor, and cognitive data from identical regions in the two brain hemispheres. ${ }^{1}$ Corpus callosum consists of 200-350 million nerve fibers in man. ${ }^{2}$ Corpus callosum is viewed as crucial in the assimilation and connection of top level data, for example, the accurate data that is required to recognize an object. ${ }^{3}$ Investigators have been interested in size diversity of corpus callosum, as estimated by area, because of the anatomical and functional implication of the corpus callosum. The territory of the corpus callosum is normally estimated at the mid sagittal cut of the brain. ${ }^{4}$ Due to the rise in number of callosotomies conducted to treat intraventricular injuries and to cure certain types of generalized epilepsy, the anatomy of the corpus callosum has revived attention in recent years. ${ }^{5}$ As corpus callosum connects identical areas of two cerebral hemispheres, thus corpus callosum is an inter-hemispheric fibres. Other commissural fibres are: anterior commissure, posterior commissure, hippocampal commissure and habenular commissure. Corpus callosum is largest of all the commissural fibres and is about $10 \mathrm{~cm}$ in length. The parts of corpus callosum from posterior to anterior are splenium, body, genu and rostrum. ${ }^{6}$ Report recommended that the size of the posterior sub-areas of the corpus callosum might be diminished in autistic people. ${ }^{7}$ Additionally, for autism, expanded mid-sagittal regions are also related with diminished autism symptom intensity, improved intellect, and higher processing speed. These outcomes propose that people with autism advantage practically from expanded corpus callosum region. 8

As indicated by different investigators, IQ representing a variety of cognitive capabilities and requiring cautious processes has been demonstrated to be impaired by corpus callosum compromise.9,10,11,12,13 Moreover, according to Tiffany M. Chaim et al,14 atrophy of corpus callosum occurs in Alzheimer's disease. Literature on the issue of the human corpus callosum's sexual dimorphism is not universal. Some investigations have discovered noteworthy gender differences in the length, shape and regions of the corpus callosum; with females having bigger splenial width than males. ${ }^{15,16,17,18,19}$ On the other hand, many researchers reported non-existence of sexual dimorphism in the size and other measurements of corpus callosum. Also, according to various studies, the change in the measurements of corpus callosum with change in age is not consistent. ${ }^{20,21,22-28}$ Age changes in particular areas of corpus callosum have been mentioned and this may point out change in inter-hemispheric fiber frameworks. The majority of the studies on morphometry of corpus callosum have been performed on Caucasian population but few studies are documented in Indian population. ${ }^{29,30}$ Moreover, studies of corpus callosum measurements are carried more on MRI imaging than on formalin fixed brain. ${ }^{31}$

The present study was conducted using formalin fixed preserved brains to get comprehensive data regarding gender, age related differences and normal range of size of corpus callosum with different measurements of brain in normal adult population in this part of northeast region of India.

\section{METHODS}

This is a descriptive study. Brain specimens were obtained from the cadavers given for dissection to the first year undergraduate medical students of Silchar Medical College and Hospital, Silchar and also from the dead bodies subjected to post-mortem examinations in the Department of Forensic Medicine, Silchar Medical College and Hospital, Silchar. The brains were removed from the cranial cavity and were preserved in $10 \%$ formalin solutions. The brain specimens from people with intracranial lesions, head injury or recorded brain pathology were excluded from the study. Only those brains with no visible gross abnormalities were included in the study. Brains were sagittaly sectioned from front to back through the septum pellucidum. The study was approved by the Institutional Ethical Committee.

\section{Measurements Recorded Using Digital Sliding Caliper}

- Anterior most point of frontal pole to posterior most point of occipital pole (AB) i.e. longitudinal diameter of brain.

- Anterior most point to posterior most point of corpus callosum (EZ) i.e. longitudinal diameter of corpus callosum.

- Anterior most point of frontal pole of brain to anterior most point of corpus callosum (AE).

- Posterior most point of occipital pole of brain to posterior most point of corpus callosum (BZ).

- Lower most point on the inferior surface and upper most point on the superior surface of the brain (CD) i.e. vertical diameter of brain.

For study purposes, corpus callosum length were divided with the method proposed by Witelson,21 in which corpus callosum has been arbitrarily divided into three regions according to maximal straight length: the anterior third (genu), the mid-third (mid-body) and the posterior third, which is divided into the posterior fifth (splenium).

\section{Measuring Height (H) of Corpus Callosum}

- $\mathrm{T}$, highest point on the superior border of corpus callosum.

- $\mathrm{R}$, inferior most point on the rostrum.

- $\mathrm{S}$, inferior most point on the splenium.

A horizontal line was taken through the inferior-most points of rostrum (R) and splenium (S); another line parallel to this was taken through the highest point (T) of corpus callosum; distance between these two lines was recorded as height of corpus callosum.

\section{Recording Widths of Corpus Callosum}

- WM, width of body at the midpoint of corpus callosum. Midpoint will be taken at half the longitudinal diameter of corpus callosum.

- WR, maximum width of rostrum of corpus callosum.

- WS, maximum width of splenium of corpus callosum.

\section{Statistical Analysis}

Statistical analysis of the data was carried out by using SPSS version 18. For all parameters, mean, standard deviation was calculated for males, females and total subjects studied. Student t- test was used to compare the means of different parameters. For $p$ value, level of significance was taken as 0.05 . 


\section{RESULTS}

37 brains were collected, out of which 24 were male \& 13 were female brains of various ages between 20 years to less than 70 years of ages. Average longitudinal \& vertical diameters of brain specimens under study were $158.29 \mathrm{~mm}$ (standard deviation 11.02) and $102.41 \mathrm{~mm}$ (standard deviation 7.88) respectively and average length of corpus callosum was 72.19 $\mathrm{mm}$ (standard deviation 5.67). Mean length of genu \& body of corpus callosum was $24.07 \mathrm{~mm}$ (i.e. EZ/3) and that of splenium was $14.44 \mathrm{~mm}$ (i.e. EZ/5). Average height of corpus callosum was $23.34 \mathrm{~mm}$ (standard deviation 2.42) and its average width at mid-body was $5.22 \mathrm{~mm}$ (standard deviation 0.68). Average width of rostrum and splenium of corpus callosum were $5.71 \mathrm{~mm}$ and $8.48 \mathrm{~mm}$ respectively. Average length of AE and BZ diameters were $36.06 \mathrm{~mm}$ and $60.73 \mathrm{~mm}$ respectively. The Pearson's coefficient of correlation between $A B \& C D, A B$ \& $A E, A B$ \& $B Z, A B$ \& EZ (figure no.4) were found to be $0.75,0.78,0.92$ and 0.57 respectively. Again, Pearson's coefficient of correlation between CD \&AE, CD \& BZ, CD \& EZ were $0.73,0.62$ and 0.59 respectively. Also, Pearson's coefficient of correlation between AE \& BZ, AE \& EZ, BZ \& EZ were $0.71,0.56$ and 0.45 respectively. All these correlation values showed that all the brain diameters were positively correlated with each other and also with the length of corpus callosum. Thus, the growth of one diameter was related with growth of another diameter and occurred in coordinated manner, so that the symmetry could be maintained. From the table no. 1 , it is evident that gender differentiation for the diameters of brain \& length of corpus callosum, is not significant with $\mathrm{p}$ value $>0.05$. Also, gender differentiation for the height \& width of corpus callosum, is not significant with $\mathrm{p}$ value $>0.05$. There is decrease in height, width of body \& splenium of corpus callosum in between 50 years to less than 60 years of ages (Table. 2).

\begin{tabular}{|c|c|c|c|c|c|c|c|c|c|}
\hline \multirow{2}{*}{\multicolumn{2}{|c|}{$\begin{array}{l}\text { Para- } \\
\text { meters }\end{array}$}} & \multicolumn{3}{|c|}{ Male } & \multicolumn{3}{|c|}{ Female } & \multirow[b]{2}{*}{$\mathbf{t}$} & \multirow[b]{2}{*}{$\mathbf{p}$} \\
\hline & & \multirow{2}{*}{\begin{tabular}{|c|}
$\begin{array}{c}\text { Min } \\
(\mathbf{m m})\end{array}$ \\
140.48 \\
\end{tabular}} & \multirow{2}{*}{$\begin{array}{c}\begin{array}{c}\text { Max } \\
(\mathbf{m m})\end{array} \\
170.01\end{array}$} & \multirow{2}{*}{$\begin{array}{c}\begin{array}{c}\text { Mean } \pm \\
\text { SD } \\
(\mathbf{m m})\end{array} \\
159.83 \pm 9.17\end{array}$} & \multirow{2}{*}{$\begin{array}{c}\begin{array}{c}\text { Min } \\
(\mathbf{m m})\end{array} \\
140.53 \\
\end{array}$} & \multirow{2}{*}{$\begin{array}{l}\begin{array}{c}\text { Max } \\
(\mathbf{m m})\end{array} \\
178.22\end{array}$} & \multirow{2}{*}{\begin{tabular}{|c} 
Mean \pm SD \\
$(\mathbf{m m})$
\end{tabular}} & & \\
\hline \multirow{4}{*}{ Brair } & $\mathrm{AB}$ & & & & & & & 1.158 & 0.255 \\
\hline & $\mathrm{CD}$ & 88.73 & 111.83 & $102.04 \pm 6.90$ & 94.05 & 125.81 & $103.10 \pm 9.71$ & 0.384 & 0.703 \\
\hline & $\mathrm{AE}$ & 30.23 & 44.12 & $36.35 \pm 4.06$ & 30.29 & 42.74 & $35.51 \pm 5.25$ & 0.541 & 0.592 \\
\hline & $\mathrm{BZ}$ & 51.37 & 65.38 & $61.61 \pm 4.12$ & 50.63 & 65.22 & $59.10 \pm 5.55$ & 1.562 & 27 \\
\hline \multirow{5}{*}{ CC } & EZ & 61.63 & 78.59 & $71.80 \pm 5.24$ & 61.49 & 85.51 & $72.93 \pm 6.53$ & 0.572 & 0.571 \\
\hline & $\mathrm{H}$ & 17.61 & 26.04 & $22.95 \pm 2.54$ & 20.81 & 26.92 & $23.99 \pm 1.68$ & 1.317 & 0.196 \\
\hline & WM & 4.37 & 6.44 & $5.24 \pm 0.63$ & 4.08 & 6.51 & $5.18 \pm 0.66$ & 0.272 & 0.787 \\
\hline & WR & 5.11 & 6.83 & $5.73 \pm 0.51$ & 4.62 & 6.56 & $5.69 \pm 0.55$ & 0.192 & 0.849 \\
\hline & WS & 6.72 & 11.61 & $8.26 \pm 1.16$ & 8.13 & 10.68 & $8.90 \pm 0.69$ & 1.835 & 0.075 \\
\hline \multicolumn{10}{|c|}{$\begin{array}{c}\text { Table 1. Showing Different Statistical Values of Diameters of Brain } \\
\text { and Corpus Callosum According to Gender }\end{array}$} \\
\hline
\end{tabular}

\begin{tabular}{|c|c|c|c|c|}
\hline \multirow{2}{*}{ Age Groups } & \multicolumn{4}{|c|}{ Parameters of Corpus Callosum } \\
\cline { 2 - 5 } & H & WM & WR & WS \\
\hline 20 to $<30$ yrs. & $23.06 \pm 0.39$ & $4.86 \pm 0.04$ & $5.46 \pm 1.21$ & $8.49 \pm 0.24$ \\
\hline 30 to $<40$ yrs. & $23.1 \pm 0.23$ & $5.29 \pm 0.50$ & $5.22 \pm 0.68$ & $8.69 \pm 0.33$ \\
\hline 40 to $<50$ yrs. & $23.24 \pm 2.29$ & $5.55 \pm 0.73$ & $5.82 \pm 0.49$ & $8.47 \pm 1.29$ \\
\hline 50 to $<60$ yrs. & $22.79 \pm 3.13$ & $4.81 \pm 0.48$ & $5.66 \pm 0.52$ & $8.03 \pm 0.82$ \\
\hline 60 to $<70$ yrs. & $23.94 \pm 2.31$ & $5.26 \pm 0.58$ & $5.51 \pm 0.22$ & $8.79 \pm 1.21$ \\
\hline \multicolumn{5}{|c|}{ Table 2. Height \& Width of Corpus Callosum } \\
According to Different Age Groups \\
\hline
\end{tabular}

\begin{tabular}{|c|c|c|c|c|c|}
\hline \multirow{2}{*}{$\begin{array}{c}\text { Age } \\
\text { Groups }\end{array}$} & \multicolumn{5}{|c|}{ Parameters of Brain and Length of Corpus Callosum } \\
\cline { 2 - 6 } & AB & CD & AE & BZ & EZ \\
\hline$<65$ yrs. & $158.34 \pm 11.07$ & $102.52 \pm 8.06$ & $35.85 \pm 4.29$ & $60.86 \pm 4.73$ & $72.34 \pm 5.59$ \\
\hline$\geq 65$ yrs. & $157.94 \pm 12.25$ & $101.58 \pm 7.19$ & $37.76 \pm 6.13$ & $59.63 \pm 5.53$ & $70.96 \pm 7.00$ \\
\hline \multicolumn{5}{|c|}{ Table 3. Diameters of Brain \& Length of Corpus Callosum } \\
According to Age Groups \\
\hline
\end{tabular}

There is decrease in length of corpus callosum (EZ) in 65+ years of age groups (Table. 3 ).

\section{DISCUSSION}

Corpus callosum has been the focal point of considerable lot of research and discussion, particularly its morphology in connection to age and sex. ${ }^{31}$ Anagnostopoulou $S$ et al. published similar study \& found positive correlation between lengths of corpus callosum with longitudinal diameter of brain. They also proposed that by applying their analogies \& quotes on MRI images, it could be easier to define anterior corpus callosum $\&$ perform anterior callosotomy. ${ }^{32}$ There is a positive correlation between the size of corpus callosum and the size of brain, a finding which is consistent with the findings of the study of Estruch et al. ${ }^{33}$ From the clinical perspective, these findings recommend that corpus callosum can be found in a specific area in brain hemisphere, contingent upon the size itself and that of the brain, a knowledge that is significant in callosotomy operations for epilepsy cases. ${ }^{34,35}$ The first research of the corpus callosum in connection to sexual differentiation was by Bean RB, a Philadelphia anatomist, who recommended in 1906 that "exceptional size of the corpus callosum may mean exceptional intellectual activity" and that there were quantifiable contrasts among male and female. ${ }^{36}$ In almost all studies on sexual dimorphism, splenium has received more attention than any other part of the corpus callosum. Some studies have reported greater splenial width and area in females.15,16,17,19 In Bishop and Wahlstein ${ }^{36}$ research, based on 19 independent human corpus callosum studies, it was concluded that there is insufficient evidence to support the existence of gender-related variations in the size or shape of splenium, regardless of the disparity in the average brain size of both sexes.

Luders et $\mathrm{al}^{22}$ additionally recommended that impact of individual varieties in callosal size was enormous enough to out range any impact of splenial size differentiation among men and women. Witelson ${ }^{21}$ also did not report any sex related differences in splenial areas, either in absolute size or size proportional to brain weight. Similarly, the Japanese ${ }^{37}$ and Indian ${ }^{29,30}$ studies also failed to find gender related difference in splenium. Corpus Callosum size changes in relation to aging adults are controversial. Although many studies have concluded that age related corpus callosal thinning is moderate, 20,27 on the other hand, some studies have reported that it is statistically significant. ${ }^{26,28}$ Most cross sectional MRI studies of the corpus callosum fail to show age related thinning in adults from $3^{\text {rd }} 7^{\text {th }}$ decade. ${ }^{27}$ In contrast some studies ${ }^{26,28}$ have shown senile effects over $3^{\text {rd }} 8^{\text {th }}$ decades. Others ${ }^{19}$ have found age related changes in elderly population especially individuals having more than 55 years of age. Several studies ${ }^{28}$ found a greater susceptibility to aging in the anterior regions of the corpus callosum than in the posterior regions.

\section{CONCLUSIONS}

Positive linear correlation was observed between length of corpus callosum and the length \& vertical diameters of brain. The study has failed to establish statistically significant gender 
differentiation in the diameters of corpus callosum. Also, there was decrease in the length of corpus callosum (EZ) in 65 years and above age group with decrease in height and width of body as well as splenium of corpus callosum between 50 - 60 years age group.

\section{REFERENCES}

[1] Ozdemir S, Ercan I, Sevinc 0, et al. Statistical shape analysis of differences in the shape of the corpus callosum between genders. The Anatomical Record 2007;290 (7):825-30.

[2] Sperry R. Some effects of disconnecting the cerebral hemispheres. Science 1982;217 (4566):1223-6.

[3] Banich MT. Interaction between the hemispheres and its implications for the processing capacity of the brain. In: Davidson RJ, Hugdahl K, eds. The asymmetrical brain. Cambridge: MIT Press 2003: p. 261-302.

[4] Jancke L, Steinmetz H. Brain size: a possible source of inter-individual variability in corpus callosum morphology. In: Zaidel E, Iacoboni M, eds. The parallel brain: the cognitive neuroscience of the corpus callosum. Cambridge, Mass: MIT Press 2003: p. 51-63.

[5] Goncalves- Ferreira AJ, Herculano-Carvalho M, Melancia JP, et al. Corpus callosum: microsurgical anatomy and MRI. Surg Radiol Anat 2001;23 (6):409-14.

[6] Datta AK. Essentials of neuroanatomy. Current Books International: Kolkata, 2009.

[7] Egaas B, Courchesne E, Saitoh O. Reduced size of the corpus callosum in autism. Arch Neurol 1995;52 (8):794801.

[8] Prigge MBD, Lange N, Bigler ED, et al. Corpus callosum area in children and adults with autism. Res Autism Spectr Disord 2013;7 (2):221-34

[9] Dimond SJ. Depletion of attentional capacity after total commissurotomy in man. Brain 1976;99 (2):347-56.

[10] Ellenberg L, Sperry RW. Capacity for holding sustained attention following commissurotomy. Cortex 1979;15 (3):421-38.

[11] Holtzman JD, Gazzaniga MS. Dual task interactions due exclusively to limits in processing resources. Science 1982;218 (4579):1325-7.

[12] Kreuter C, Kinsbourne M, Trevarthen C. Are deconnected cerebral hemispheres independent channels? A preliminary study of the effect of unilateral loading on bilateral finger tapping. Neuropsychologia 1972;10 (4):453-61.

[13] Teng EL, Sperry RW. Interhemispheric interaction during simultaneous bilateral presentation of letters or digits in commissurotomized patients. Neuropsychologici 1973;11 (2):131-40.

[14] Chaim TM, Duran FLS, Uchida RR, et al. Volumetric reduction of the corpus callosum in Alzheimer's disease in vivo as assessed with voxel-based morphometry. Psychiatry Research: Neuroimaging 2007;154 (1):59-68.

[15] DeLacoste-Utamsing C, Holloway RL. Sexual dimorphism in the human corpus callosum. Science 1982;216 (4553):1431-2.
[16] Going JJ, Dixson A. Morphometry of the adult human corpus callosum: lack of sexual dimorphism. J Anat 1990;171:163-7.

[17] Allen LS, Richey MF, Chai YM, et al. Sex differences in the corpus callosum of the living human being. J Neurosci 1991;11 (4):933-42.

[18] Holloway RL, Anderson PJ, Defendini R, et al. Sexual dimorphism of the human corpus callosum from three independent samples: Relative size of the corpus callosum. Am J Phys Anthropol 1993;92 (4):481-98.

[19] Davatzikos C, Resnick SM. Sex difference in anatomic measures of inter-hemispheric connectivity: correlations with cognition in women but not men. Cereb Cortex 1998;8 (7):635-40.

[20] Sullivan EV, Rosenbloom MJ, Desmond JE, et al. Sex differences in corpus callosum size: relationship to age and intracranial size. Neurobiol Aging 2001;22 (4):60311.

[21] Witelson SF. Hand and sex differences in the isthmus and genu of the human corpus callosum. A Postmortem Morphological Study. Brain 1989;112 (Pt 3):799-835.

[22] Luders E, Rex DE, Narr KL, et al. Relationships between sulcal asymmetries and corpus callosum size: gender and handedness effects. Cereb Cortex 2003;13 (10):1084-93.

[23] Bean RB. Some racial peculiarities of the Negro brain. Am J Anat 1906;5:353-432.

[24] Oppenheim JS, Lee BC, Nass R, et al. No sex related differences in human corpus callosum based on magnetic resonance imagery. Ann Neurol 1987;21 (6):604-6.

[25] Byne W, Bleier R, Houston L. Variations in human corpus callosum do not predict gender: a study using magnetic resonance imaging. Behav Neurosci 1988;102 (2):222-7.

[26] Doraiswamy PM, Figiel GS, Husain MM, et al. Aging of the human corpus callosum magnetic resonance imaging in normal volunteers. J Neuropsychiatr Clin Neurosci 1991;3 (4):392-7.

[27] Pfefferbaum A, Lim KO, Desmond JE, et al. Thinning of the corpus callosum in older alcoholic men: a magnetic resonance imaging study. Alcohol Clin Exp Res 1996;20 (4):752-7.

[28] Weis S, Kimbacher M, Wenger E, et al. Morphometric analysis of the corpus callosum using MR: Correlation of measurement with aging in healthy individuals. Am J Neuroradiol 1993;14 (3):637-45.

[29] Banka S, Jit I. Sexual dimorphism in the size of the corpus callosum. J Anat Soc India 1996;45:77-85.

[30] Suganthy J, Raghuram L, Antonisamy B, et al. Gender and age related differences in the morphology of the corpus callosum. Clin Anat 2003;16 (5):396-403.

[31] Gupta T, Singh B, Kapoor K, et al. Corpus callosum morphometry: corpus callosum morphometry: comparison of fresh brain, preserved brain and magnetic resonance imaging values. Anatomical Science International 2008;83 (3):162-8.

[32] Anagnostopoulou S, Mourgela S, Katritsis D. Morphometry of corpus callosum: an anatomical study. Neuroanatomy 2006;5:20-3.

[33] Estruch R, Nicolas JM, Salamero M, et al. Atrophy of the corpus callosum in chronic alcoholism. J Neurol Sci 1997;146 (2):145-51. 
[34] Cowell PE, Allen LS, Kertesz A, et al. Human corpus callosum: a stable mathematical model of regional neuroanatomy. Brain Cogn 1994;25 (1):52-66.

[35] Morino M, Shimizu H, Ohata K, et al. Anatomical analysis of different hemispherotomy procedures based on dissection of cadaveric brains. J Neurosurg 2002;97 (2):423-31.
[36] Bishop KM, Wahlsten D. Sex differences in the human corpus callosum: myth or reality? Neurosci Biobehav Rev 1997;21 (5):581-601.

[37] Takeda S, Hirashima Y, Ikeda H, et al. Determination of indices of the corpus callosum associated with normal aging in Japanese individuals. Neuroradiol 2003;45 (8):513-8. 